\title{
Expanding Access to the Management of HIV/ AIDS through Physicians in Private Practice: An Exploratory Survey of Knowledge and Practices in Two N igerian States
}

\author{
CA Ihek weaz $u^{1}$ and $D$ Stark $e^{1}$
}

\begin{abstract}
ABST RACT
O ver the past few years, the cost of antiretroviral drugs has continued to decline. A significant proportion of people in $\mathrm{N}$ igeria seek medical care primarily in the "for profit" private sector. The complexity of managing HIV and AID S has led to debates on whether care should only be restricted to trained and accredited experts in HIV care. This research studied the knowledge and practices of physicians in private practice in two $\mathrm{N}$ igerian states on the management of patients with HIV / A ID S using an anonymous self-administered questionnaire eliciting knowledge and attitudinal information. This is to ascertain their preparedness to manage HIV positive patients. The doctors were found to be poorly informed on practical issues in the management of HIV patients. These included the need to confirm their patient's HIV status, where to do the confirmation and where to refer such patients for counselling. M ost of them referred to the mass media as their primary source of information. There is an urgent need for pro-active planning to prepare physicians in private practice for increasing demands in the management of HIV/ AIDS in N igeria. O rganising a nation-wide training programme that would lead to ongoing accreditation programme is a way of achieving this. The formulation of guidelines for managing both clinical and non-clinical aspects of HIV / ADS should be prioritised. (A fr J R eprod H ealth 2005; 9[2]: 141-150)
\end{abstract}

\section{RÉ SUMÉ}

Au cours de ces dernières années, le coût des médicaments antéretroviraux ne cesse de baisser. Bon nombre de gens au $\mathrm{N}$ igéria ne recherchent les soins médicaux que dans le secteur privé à but lucrative. La complexité du traitement du VIH / SIDA a provoqué des débats pour savoir si l'on doit limiter le traitement aux experts formés et autorisés à traiter le VIH . $N$ ous avons étudié, dans cette recherche, la connaissance, et les pratiques des médecins en pratique privée dans deux états nigérians sur le traitement des patients infectés par leVIH / SI DA à l'aide d'un questionnaire anonyme auto-administré afin d'obtenir des renseignements sur la connaissance et l'attitude. Ceci pour déterminer leur disposition à traiter les patients séropositifs. On trouve que les médecins étaient mal-renseignés sur les questions pratiques concernant le traitement des patients atteints par le VIH. Ceci comprend la nécessité de confirmer si le patient est séropositif ou non, là où l'on peut le confirmer et là où il faut envoyer le patient pour le conseil. La plupart d'entre eux ont indiquéque les médias étaient leur source primaire de renseignement. II y a une nécessité urgente d'avoir une planification pro-active pour former les médecins privées afin de s'occuper des demandes du traitement du VIH / SI DA au N igéria. Une façon d'accomplir cette tâche est d'organiser un programme de formation partout dans le pays qui conduira à un programme d'habilitation suivi. II faut donner la priorité à la formulation des directives concernant le traitement des aspects cliniques et non-cliniques du VIH/SIDA. (Rev A fr Santé Reprod 2005; 9[2]: 141-150)

KEY WoRdS: Counselling, H IV , A IDS, physicians, private, practice, N igeria

${ }^{1} \mathrm{H}$ einrich $H$ eine U niversity, D üsseldorf, D üsseldorf, $G$ ermany

Correspondence: Chik we Ihek weazu, F ellow of the E uropean Programme for Intervention E pidemiology (E PIE T), H ealth Protection A gency, South W est, The W heelhouse, Bonds M ill, Stonehouse, Stroud G L 103R F, UK. Tel: +44 (0) 1453829740; F ax: + 44 (0) 1453829741; E mail: chikweihekweazu@ hpa.org.uk 


\section{Introduction}

Undoubtedly, HIV / AIDS represents one of the greatest public health problems that will face $\mathrm{Ni}$ geria in the next century. HIV prevalence information has been available among antenatal clinic attendees since the mid-1980s. Prevalence initially remained low for many years. From 1988 to 1990, $1 \%$ of antenatal women tested positive for HIV, but by 2003 the figure had risen to $5.4 \% .{ }^{1}$ The 20-24-year age group is the most affected, with no significant difference in prevalence between the rural and urban areas. The estimated number of adults and children living with HIV / AIDS in $\mathrm{N}$ igeria was 3.6 million at the end 2003. ${ }^{1}$

H IV prevention strategies depend on targeted prevention for all people at risk of the infection and early detection, care and support for those al ready living with HIV. The prevention of new infections and care of those already affected are linked and complimentary. The expanding access to treatment in resource poor settings offers a critical opportunity to simultaneously strengthen HIV prevention efforts. ${ }^{2}$ In the $\mathrm{N}$ igerian public sector there is an ongoing scheme to treat about 15,000 people with antiretroviral drugs. ${ }^{3} \mathrm{H}$ owever, in the private sector, HIV positive patients still lack medical and social support.

In almost every other sector in $\mathrm{N}$ igeria, there has been a growing trend towards privatisation. Privatisation and commercialisation form the major focus of the present government's policies, and the medical profession is not immune to this paradigm shift.

The private health care sector in N igeria has essentially been excluded from policy formulation, and there has been little control on the activities of private sector health care providers. ${ }^{4}$ Services are paid for directly out-of-pocket in most instances. ${ }^{5}$ There is little hindrance to the supply of poor quality of care. The exact extent of the private sector's participation in the provision of health care in $\mathrm{N}$ igeria is difficult to estimate, but approximate figures have put the private sector's spending at three to four times the amount of public expenditure. ${ }^{6}$ World Bank reports estimate that in $1990,60 \%$ of total health

coos seupu A S.o h e . $10 \mathrm{~V}$ तjा expenditure was from private sources. ${ }^{7}$ Private clinics are concentrated in the cities and medical services provided are often perceived as any other article of trade. $^{8}$

This study was conducted to assess the knowledge and experiences of physicians in private practice with HIV/ AID S patients in N igeria. It was to assess their role in themanagement of such patients and in prevention. Theresults could serve as a guide in providing direction for training opportunities.

\section{Methods}

Q uestionnaire Content and $\mathrm{A}$ dministration

A closed answer questionnaire was developed and used to obtain information for the study. A mailed questionnaire might indeed have been more suitable for this study but for the unreliability of the N igerian postal system. U sing telephones was also considered but it would produce a large bias because of the low telephone density in N igeria. A knowledge score was built from the six questions asked on various aspects of HIV/AIDS. This score was analysed using a multiple regression model. The regressors included sex, social contact with a person living with HIV/AIDS, type of practice, full or part-time practice, as well as the number of years in practice.

Sample Selection and D ata Collection Procedures

The study was conducted among physicians in private practice in I mo and A bia States of southeastern $\mathrm{N}$ igeria. A sampling frame of physicians in private practice in the two states was not possible because such data were not available from the states' ministries of health. Therefore, a convenient sample of 147 physicians in private practice was used.

$D$ ata A nalysis

Statistical analysis for this study was done using SPSS (Statistical Package for Social Sciences) version 10.0 statistical programme. 


\section{Results}

Most of the physicians sampled $(72.6 \%)$ were males, and in solo practices (73.3\%). The demographic characteristics of the physicians are as shown in Table 1.

Table 1 Demographic Characteristics of Respondents

\begin{tabular}{lr}
\hline Characteristic & Percentage \\
\hline Sex of respondent & \\
M ale & 72.6 \\
Female & 27.4 \\
Type of private practice & \\
Single practice & 73.3 \\
G roup practice & 26.7 \\
C linical specialisation & \\
Yes & 39.7 \\
N o & 60.3 \\
Type of practice & \\
Full time & 63 \\
Part time & 37 \\
Sodial contact with PL H WA ? & \\
Yes & 24.7 \\
N o & 75.3 \\
Years in private practice & \\
$<5$ & 24 \\
$5-10$ & 40.4 \\
$10-20$ & 28.8 \\
$20-30$ & 6.8 \\
$>30$ & 0 \\
\hline
\end{tabular}

Of all the physicians in private practice surveyed, $68 \%$ had seen at least one patient with clinical AID S (79\% had seen patients with a H IV positive test) in their clinic in the last one year, with as many as $21 \%$ having reported seeing more than six patients (F igure 1). Surprisingly, 25\% of the respondents admitted to having some social contact with a person living with HIV or AID S (PLWHA) outside clinical practice. Of the 146 respondents, only $15(10 \%)$ said that they attempted to treat patients with antiretroviral drugs.
Only $12 \%$ of the respondents had any idea of where to refer patients for their non-clinical needs such as counselling. The results relating to where physicians sent their patients for HIV tests and what was necessary to confirm their patients' serostatus were interesting in their diversity (Figure 2). There was confusion by physicians in providing answer to the question: "What do I require to confirm a HIV positive diagnosis". There was no obvious consensus on which tests or how many tests are necessary (F igure 3). A nother noteworthy finding was the answers provided to the question on the most important source of information on matters relating to HIV/ AIDS (Figure 4). Most of them said they got their information from the mass media (34\%).

0 ther questions evaluated the physicians' knowledge of important aspects of the AIDS epidemic. Q uestions on modes of transmission were deliberately left out; as they would no longer be valid indicators of HIV-related knowledge due to the wide publicity given to the epidemic especially among the medical profession. Between $57 \%$ and $82 \%$ of the questions were answered correctly by the respondents (Figure 5).

The results showed that there are large gaps in knowledge about HIV/AIDS among the physicians. A large percentage of them (57\%) did not know the adult prevalence rate in $\mathrm{N}$ igeria despite the fact that biannual sentinel surveys have been conducted in $\mathrm{N}$ igeria over the past several years. Twenty per cent of the physicians did not realise that every person confirmed to beinfected with HIV, even if managed with ARV s, will eventually develop AIDS.

Eighteen per cent of the respondents did not know the window period (the time between infection and sero-conversion), and only $76 \%$ of the physicians were aware that the risk of becoming infected with HIV during unprotected vaginal intercourse is as much as 2- 4 times higher for women than men. 


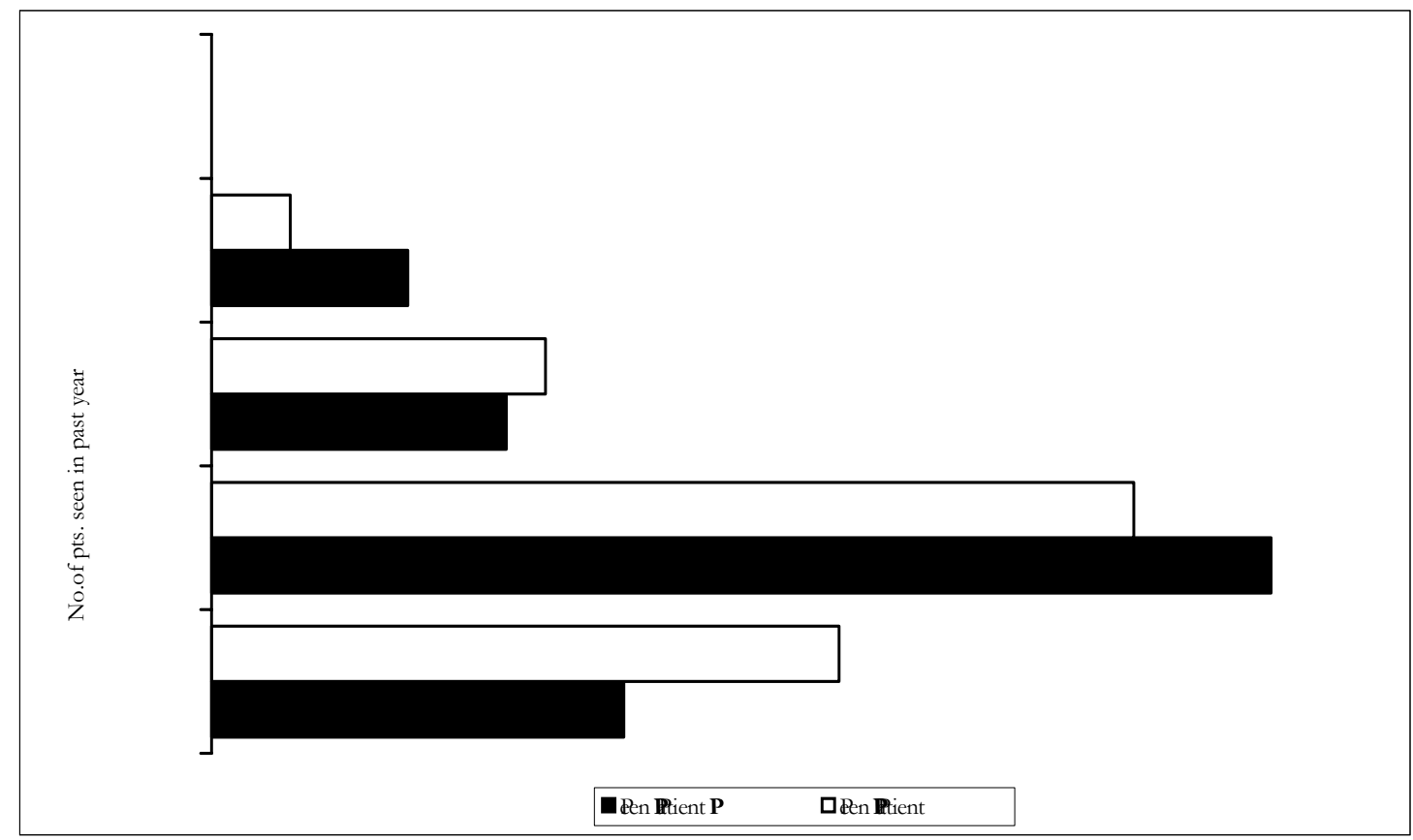

F igure 1 N umber of Patients with H IV/ AIDS Seen by each Physician in the Last One Year

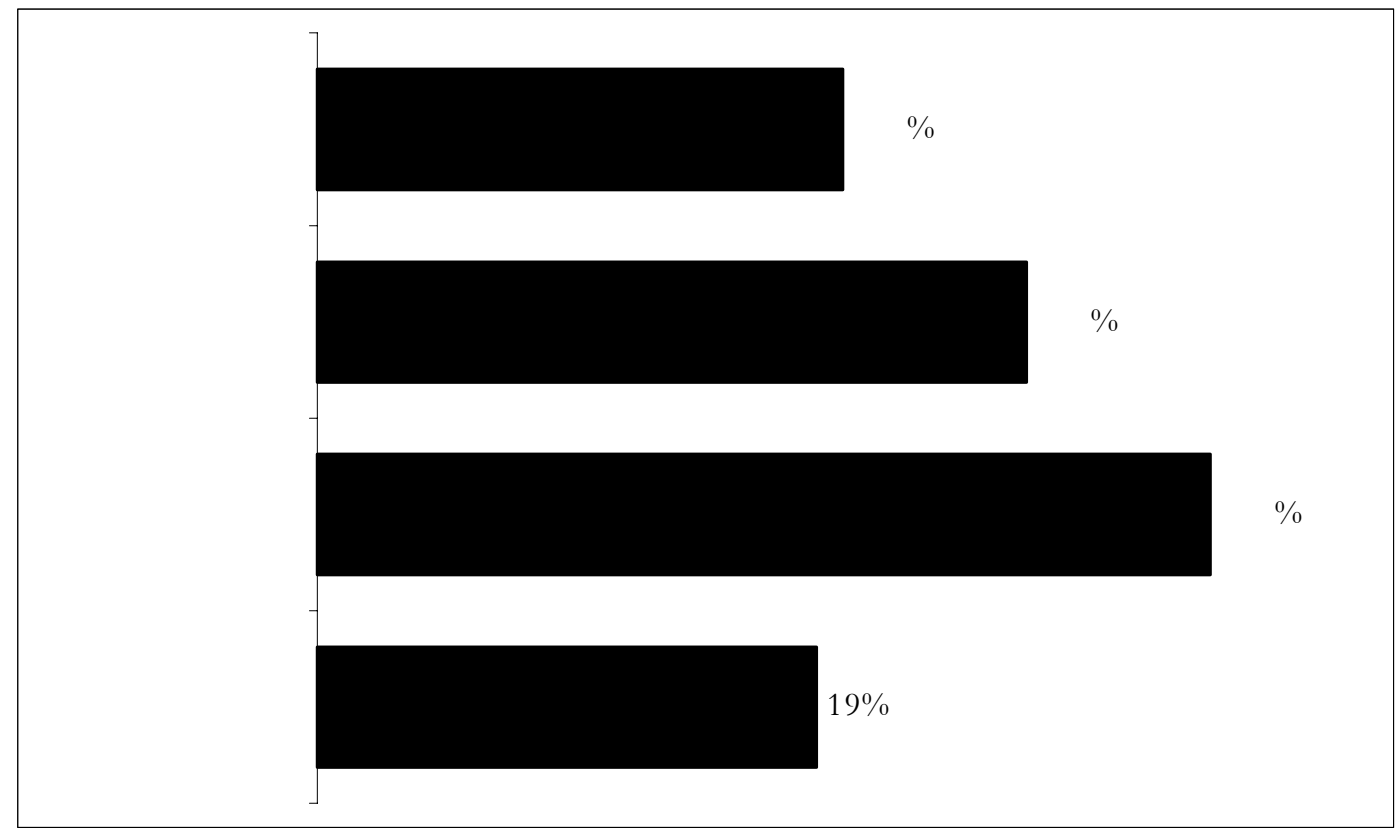

F igure 2 Where Patients were Sent to for their HIV Tests

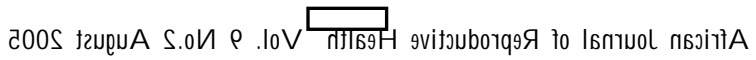




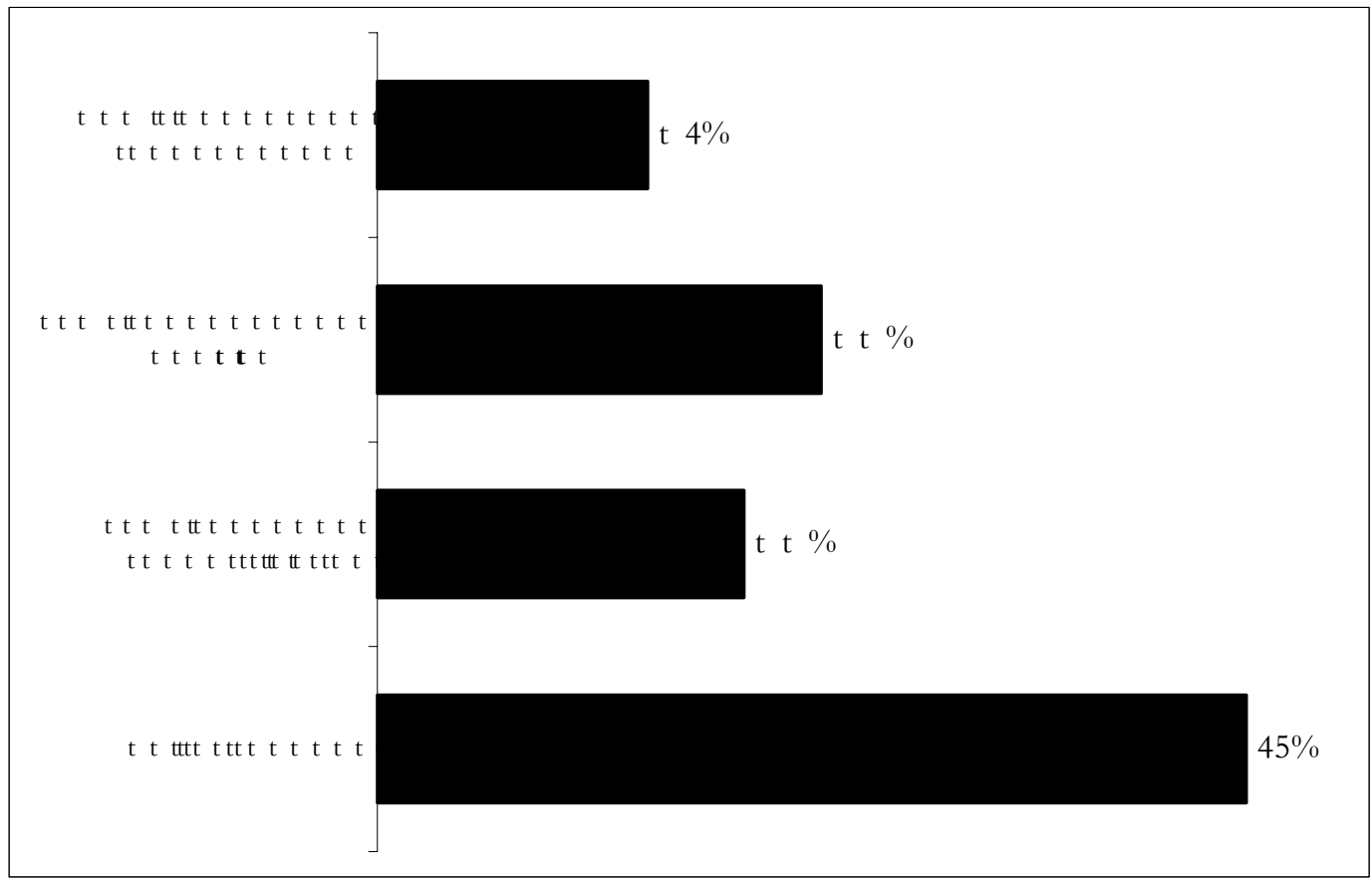

Figure 3 H ow HIV Positive Diagnosis was Confirmed

Table $2 \quad$ Knowledge Score on HIV/ AIDS by Physicians ( aximum score $=6$ )

\begin{tabular}{lrrr}
\hline Score & Frequency of score & \% of score & Cumulative \% \\
\hline 6 & 31 & 21.2 & 21.2 \\
5 & 34 & 23.3 & 44.5 \\
4 & 32 & 21.9 & 66.4 \\
3 & 35 & 24.0 & 90.4 \\
2 & 6 & 4.1 & 94.5 \\
1 & 5 & 3.4 & 97.9 \\
0 & 3 & 2.1 & 100 \\
\hline
\end{tabular}

A knowledge score was then calculated, giving one point to a correct answer and zero to an incorrect answer, including the option of "I don't know". The knowledge score was calculated for the six variables. These results are presented in Table $2.0 \mathrm{f}$ all the respondents, $21.2 \%$ got all the answers correct while $66.4 \%$ got only half.

To evaluate which of the demographic variables were independently associated with respondents' knowledge of HIV, an inclusive mul- tiple regression model was used. The dependent variable was the knowledge score, and the independent variables were sex, single or group practice, general practitioner or specialist, full or parttime practice, years of practice, number of patients living with AID S seen in the last year and, social contact with person living with HIV / AIDS. The regression was a rather poor fit $\left(\mathrm{R}^{2}\right.$ adj. = $25 \%$ ), but the overall relationship was significant (F 7,137 = 7.78, $p=<0.001)$. The factors found 
to have a significant positive association with the knowledge score were: social contact with a person living with HIV, less years of private practice, and the number of PLWAs seen in the last year (Table 3).

O ne important factor stands out from Table 3. Respondents' knowledge of HIV issues was negatively related to the number of years in practice, i.e., the more the number of years in practice, the poorer the respondents' knowledge of HIV/AIDS. This is not surprising, as the disease is relatively new and those physicians who have been in practice for upwards of 10 years, and have probably been out of the formal train- ing system are less knowledgeable about the disease than their younger colleagues.

The physicians' need for additional training and the means by which it would preferably be delivered was assessed. Most (91\%) of them respondents felt the need for additional training in HIV / AIDS and they ranked information on clinical presentation and management as the most critical information needed. The rest of the rankings are shown on Table 4.

The preferred modes of delivery were training courses and workshops, while booklets with guidelines were ranked second.

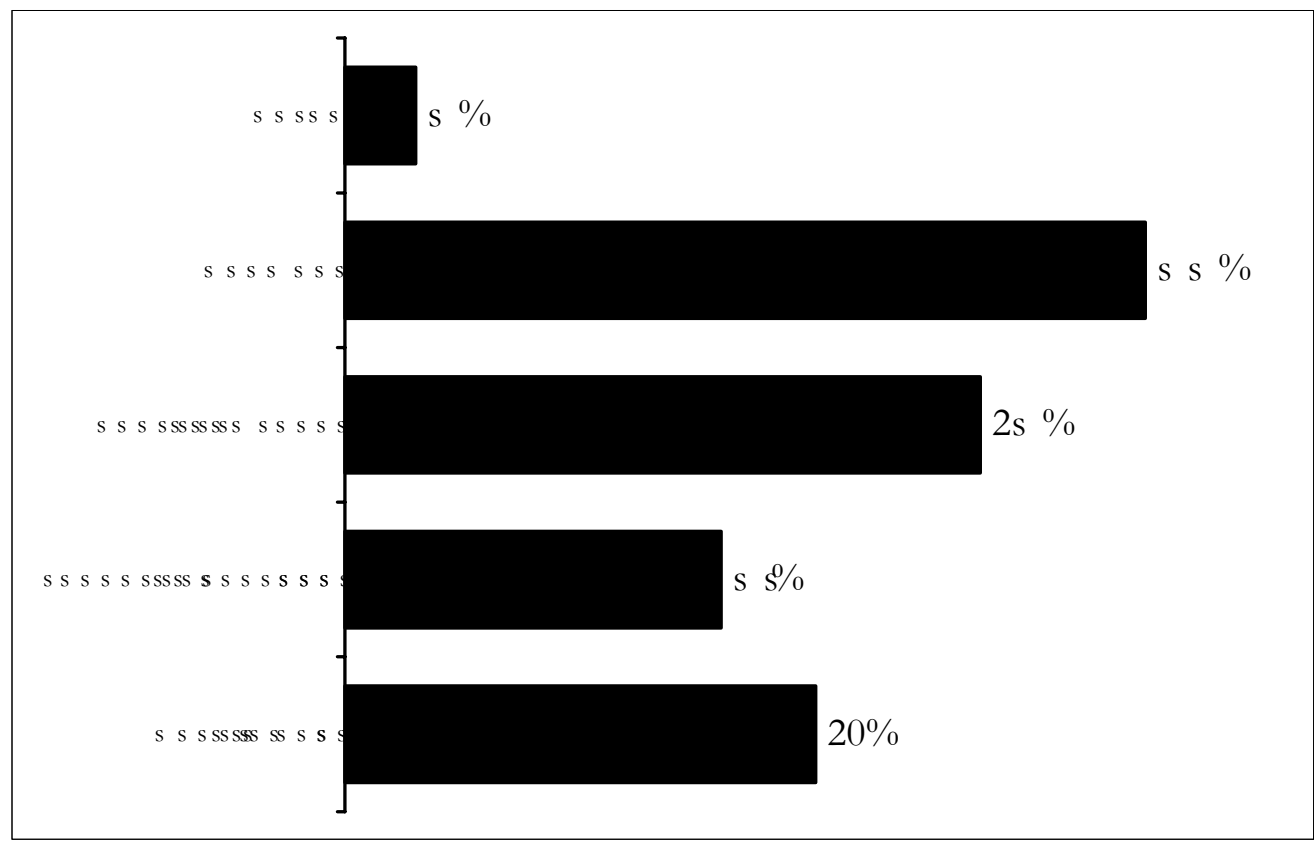

Figure 4 Most Important Sources of Information on Matters Relating to H IV/ AIDS

Table 3 Positive Associations with Knowledge of HIV

\begin{tabular}{lrrr}
\hline Factor & $\begin{array}{r}\text { Non-standardised } \\
\text { B coefficient }\end{array}$ & $\begin{array}{r}\text { Standardised } \\
\text { beta } \\
\text { coefficient }\end{array}$ & p value \\
\hline Social contact with PLWA & & 0.278 & $<0.001$ \\
Years of private practice & 0.909 & -0.223 & 0.003 \\
N o. of PLWA s seen in last year & -0.359 & 0.221 & 0.008 \\
\hline
\end{tabular}

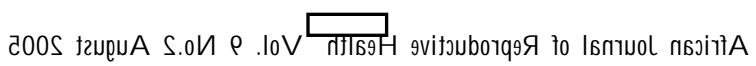




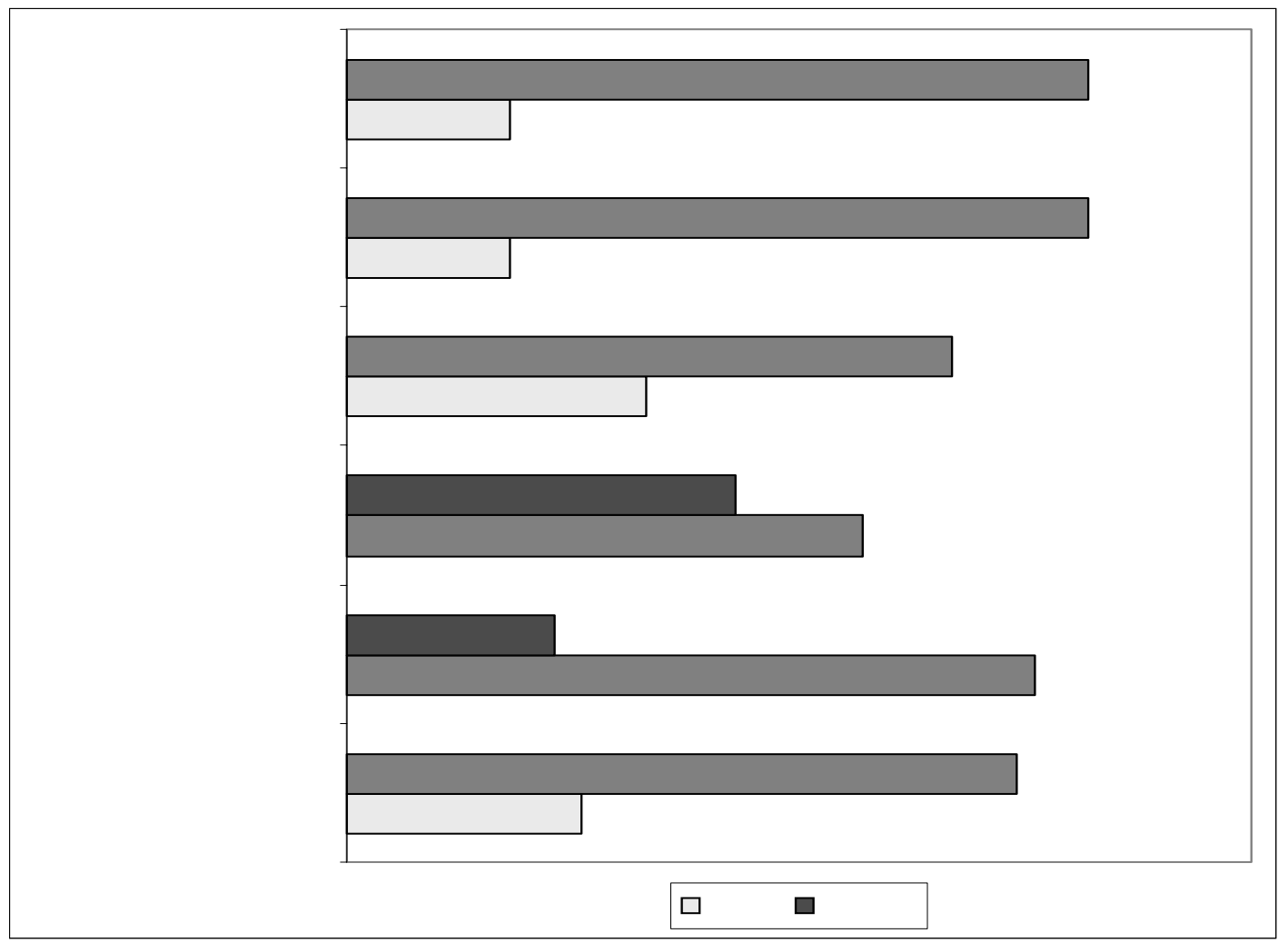

Figure $5 \quad$ HIV/AIDS Knowledge among the Physicians (chequered pattern signifies correct answer)

Table 4 Physicians' Ranking of Information $\mathrm{N}$ eeds on Clinical Presentation and $\mathrm{M}$ anagement of HIV/AIDS

\begin{tabular}{lll}
\hline Rank & Information need & $\%$ \\
\hline 1 & Information on clinical presentation and management & 44 \\
2 & D irectory of available H IV / A ID S related services & 23 \\
3 & Information material on counselling & 18 \\
4 & Regular bulletins on recent advances & 15 \\
\hline
\end{tabular}

\section{Discussion}

The objective of this study was to throw more light on the hindrances to the management of HIV/AIDS in the private health care sector in $\mathrm{N}$ igeria. While the barriers in terms of knowledge and attitude are substantial, the study showed that frequent contact with PLWAs both profes- sionally and socially drives the search for more knowledge on HIV/AIDS.

Proper assessment of an individual's HIV status permits preventive measures to enable HIV negative persons to remain negative and positive persons to enter into care. ${ }^{9}$ The later, in turn, facilitates efforts to prevent secondary transmission. The private sector has continually gained relevance 
in health care delivery in N igeria over the past 15 years. The prevailing economic situation has lead to many physicians treating only patients that can afford to pay. ${ }^{5}$ This study shows that physicians in private practice are not yet adequately prepared to effectively take on the management of HIV/ AIDS in Nigeria. Studies in other African countries where antiretrovirals are becoming increasingly available have described similar problems. These include "therapeutic anarchy", montherapy, treating without tests to monitor progress and intermittent treatment in the private sector. ${ }^{10}$

There are several factors that make private practitioners the first choice for most $\mathrm{N}$ igerians seeking care. They are often more conveniently located especially for those living in the urban areas, opening hours are longer and consultations are thought to be more private and confidential. ${ }^{11-13}$ $M$ any studies have charted the health-seeking behaviour of symptomatic individuals, often identifying that perceived service barriers or apparent conveniences leads them to undertake inappropriate initial attempts at treatment. ${ }^{14}$

Studies in the late 80's in Europe, the A mericas and A ustralia have shown that even in these countries with elaborate continuous medical education, medical practitioners often do not have accurate knowledge of HIV. ${ }^{15-17}$ There is paucity of recent studies on this issue, but the few that exist indicate that there has hardly been any improvement in this trend with time. ${ }^{18}$

A general trend can be recognised in most of these countries. The emphasis has shifted from educating every doctor on the management of HIV/ AIDS to a few super specialists. This can partly be attributed to the rapid rate of research into HIV / AIDS and its consequences on clinical management in societies where such management options are readily available. This seems to be the trend in the west as a result of the increasing complexity in the clinical management of HIV/ AIDS with the advent of highly active antiretroviral therapy (HAART). ${ }^{19}$
The few available studies in Nigeria show uncertainty on the management of HIV/ AIDS. In one study, $54-64 \%$ of physicians working in a teaching hospital setting felt that they should be allowed to decide by themselves whether they should treat patients infected with H IV, while 46$49 \%$ believed that refusing to take care of such patients was not unethical. ${ }^{20} \mathrm{~A}$ nother paper came to the conclusion that there is an urgent need for interdisciplinary collaboration among health care professionals to enhance prompt referral and treatment of AID S patients. ${ }^{21}$

This study shows that there are still significant gaps in knowledge and practice in the management of patients with HIV/AIDS. The private sector is already playing a very important role in health care delivery in $\mathrm{N}$ igeria. H owever, in this era of HIV/AIDS, management cannot be allowed to follow the haphazard practice as with other health problems or there will be direct consequences both for the individual patient and the society.

Physicians in privatepractice are often ignored when planning for health care services in developing countries. This is in spite of the fact that they are the major providers of health care services in most of these countries. It is often assumed too that only the very rich have access to these doctors. This is a misconception. In N igeria, the first consultation is often cheaper when attending a private clinic than a public clinic and the opening hours are more convenient. ${ }^{12}$ Yet this sector is almost always ignored when planning for improvements in health care services.

At this crucial time, when there is a growing consensus that prevention and treatment are not two independent strands in the efforts to quell the spread of HIV/AIDS, but are interdependent arms of the same effort, progress will be difficult if physicians in private practice are ignored. Results of this study, however, show that if this potential is to be fully explored to maximum benefit, a lot more effort has to be put into providing them adequate training, and 
structuring the system of referrals in such a way as to increase the benefit for the patient.

O ne major limitation of this study was the use of a convenient sample. This was because of the absence of a database of physicians in private practice in the states where the study took place with accurate demographic information.

\section{Recommendations}

Systems of organising and governing the practice of private sector providers are urgently needed in this era of HIV/AIDS. O ne of the major findings of this study is that a large number of physicians are eager to improve their knowledge and skills in order to fulfil their vital role in the prevention and management of HIV and AID S. Physicians require accurate, correct and regular information on all aspects of HIV / AIDS.

E ducation programmes aimed at disseminating such information need to be developed and implemented rapidly. It is obvious that few private practitioners in $\mathrm{N}$ igeria have any structures that enable them to keep up-to-date after their qualification, despite the felt need for it, as depicted by this study. There is, therefore, an urgent need for the training and sensitisation of physicians on important issues in HIV / AID S.

It might not be feasible to do this for all physicians in private practice. A solution to this can be an accreditation programme. This has been successfully carried out in several countries. ${ }^{22,23}$ This will hopefully guarantee a minimum level of competency in a certain number of certified physicians in private practice in the complicated field of managing patients living with HIV / AIDS.

A nother possible aide would be the formulation of management guidelines, not just in terms of treatment but also for other services required by people living with HIV/AIDS, as well as instructions for patients on how to access these services.

Finally, there is an urgent need to establish and maintain a database of physicians in private practice in $\mathrm{N}$ igeria containing basic demographic information. This will not only facilitate research as this one, but will also enable more efficient planning and equitable distribution of resources.

\section{References}

1. UN AIDS. E pidemiological Fact Sheets: $\mathrm{N}$ igeria, 2004 Update. http:/ / www.unaids.org/ E N / other/ functionalities/ Searc/ asp.

2. G ayle H and JM Lange. Seizing theopportunity to capitalise on the growing access to H IV treatment to expand HIV prevention. L ancet 2004; 364(9428): 6-8.

3. Associated Press Information Services. N igeria launching largest AID S program. 2001.

4. O gunbekun I, A 0 gunbekun and $\mathrm{N} O$ robaton. Private health care in N igeria: walking the tightrope. H ealth Policy Plan 1999; 14(2): 174-181.

5. O nwujekwe $O$ and $B$ Uzochukwu. Socio-economic and geographic differentials in costs and payment strategies for primary healthcare services in Southeast N igeria. H ealth Policy 2005; 71(3): 383397.

6. A kin JS, N Birdsall and $D$ de Feranti. Financing health services in developing countries: an agenda for reform. W orld B ank R eports 1995.

7. World Bank. Better health in Africa: experiences and lessons learned. W orld B ank R eports 1994.

8. Alubo SO. Doctoring as business: a study of entrepreneurial medicine in N igeria. M ed A nthropol 1990; 12(3): 305-324.

9. Wight RG, et al. Screening for transmission behaviors among H IV-infected adults. A ID S E duc Prev 2000; 12(5): 431-441.

10. B rugha R. A ntiretroviral treatment in developing countries: the peril of neglecting private providers. B r M ed J 2003; 326(7403): 1382-84.

11. Brieger WR. Clarifying the case on the role and limitations of private health care in $\mathrm{N}$ igeria. $\mathrm{H}$ ealth Policy Plan 2002; 17(2): 218-219.

12. A lubo 0 . The promise and limits of private medicine: health policy dilemmas in $\mathrm{N}$ igeria. $\mathrm{H}$ ealth Policy Plan 2001; 16(3): 313-321.

13. Brugha $R$. and $A Z$ wi. Improving the quality of private sector delivery of public health services: challenges and strategies. H ealth P olicy Plan 1998; 13(2): 107- 120. 
14. A wusabo-A sare $K$ and JK A narfi. H ealth-seeking behaviour of persons with HIV / AID S in G hana. $H$ ealth Transit Rev 1997; 7 (Supp): 243-256.

15. Searle ES. K nowledge, attitudes, and behaviour of health professionals in relation to AIDS. L ancet 1987; 1(8523): 26-28.

16. $M$ ilne RI and SM K een. A re general practitioners ready to prevent the spread of HIV ? B r M ed J 1988; 296(6621): 533-535.

17. Anderson $P$ and $R$ Mayon-White. General practitioners and management of infection with HIV. Br M ed J 1988; 296(6621): 535-537.

18. K ellock DJ and KE Rogstad. Attitudes to HIV testing in general practice. Int I ST D A ID S 1998; 9(5): 263-267.

19. Commonwealth AID S Research G rant Committee Working Party. A ttitudes, knowledge and be-

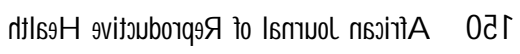

haviour of general practitioners in relation to HIV infection and AID S. M ed J A ust 1990; 153(1): 512.

20. O lubuyide IO. D octors at risk of hepatitis $B$ and H IV infection from patients in N igeria. J $R$ Soc $H$ ealth 1996; 116(3): 157-60.

21. SoteE O. AID S and infection control: experiences, attitudes, knowledge and perception of occupational hazards among $\mathrm{N}$ igerian dentists. $\mathrm{A}$ fr $\mathrm{D}$ ent J 1992; 6: 1-7.

22. Physicians' group launches HIV training, certification program. A ID S Policy L aw 2001; 16(9): 5.

23. Bain BC. I mproving community care for persons with the acquired immunodeficiency syndrome in Jamaica. W Ind M ed J 1998; 47(Supp. 4): 37-39. 